\title{
Language Choice and Use of Malaysian Public University Lecturers in the Education Domain
}

\author{
Tam Lee Mei \\ Faculty of Modern Languages and Communication, Universiti Putra Malaysia, Malaysia \\ E-mail: jollytam0516@gmail.com \\ Ain Nadzimah Abdullah (Corresponding author) \\ Faculty of Modern Languages and Communication, Universiti Putra Malaysia, Malaysia \\ E-mail: ain@putra.upm.edu.my \\ Chan Swee Heng \\ Faculty of Modern Languages and Communication, Universiti Putra Malaysia, Malaysia \\ E-mail: shchan@fbmk.upm.edu.my \\ Zalina Binti Mohd Kasim \\ Faculty of Modern Languages and Communication, Universiti Putra Malaysia, Malaysia \\ E-mail: zalina_mk@upm.edu.my
}

Doi:10.7575/aiac.alls.v.7n.1p.21

URL: http://dx.doi.org/10.7575/aiac.alls.v.7n.1p.21
Received: 19/08/2015

Accepted: 31/10/2015

\begin{abstract}
It is a norm for people from a multilingual and multicultural country such as Malaysia to speak at least two or more languages. Thus, the Malaysian multilingual situation resulted in speakers having to make decisions about which languages are to be used for different purposes in different domains. In order to explain the phenomenon of language choice, Fishman domain analysis (1964) was adapted into this research. According to Fishman's domain analysis, language choice and use may depend on the speaker's experiences situated in different settings, different language repertoires that are available to the speaker, different interlocutors and different topics. Such situations inevitably cause barriers and difficulties to those professionals who work in the education domain. Therefore, the purpose of this research is to explore the language choice and use of Malaysian public university lecturers in the education domain and to investigate whether any significant differences exist between ethnicity and field of study with the English language choice and use of the lecturers. 200 survey questionnaires were distributed to examine the details of the lecturers' language choice and use. The findings of this research reveal that all of the respondents generally preferred to choose and use English language in both formal and informal education domain. Besides, all of the respondents claimed that they chose and used more than one language. It is also found that ethnicity and field of study of the respondents influence the language choice and use in the education domain. In addition, this research suggested that the language and educational policy makers have been largely successful in raising the role and status of the English language as the medium of instruction in tertiary education while maintaining the Malay language as having an important role in the communicative acts, thus characterizing the lecturers' language choice and use.
\end{abstract}

Keywords: Language choice and use; lecturers; Malaysian public university, education domain; domain analysis

1. Introduction

1.1 Background of the Research

Language choice is defined as the language, variety or code utilized by a particular speech community for a particular purpose or function in verbal interaction (Fishman, 1972). In a multilingual society, individuals constantly have to make a choice of which language to use for which situation and this depends on the interlocutors who are also constrained by their own linguistic repertoires. Some people view this as a problem since it could cause barriers and difficulties in communication. Nonetheless exercising a choice in language use in different contexts can be a complex task. This is due to the fact that the speaker often has to decide constantly which languages are appropriate to use for what purposes, and the decision is often instantaneous. Besides, the speaker might be influenced by the characteristics of the interlocutor, such as ethnicity, age, gender, educational level, proficiency level and domains in which the particular communicative event takes place.

Deciding the language to use in everyday communication is not uncommon especially when the person lives in a multilingual society. Such decision would be simple by someone who lives in a monolingual society. However, people who live in a bilingual or multilingual country inevitably face more decision makings in choosing what language to use as all of the people speak more than one language. It is also common that all of them do not speak the same language. Thus, domain analysis which is proposed by Joshua Fishman (1972) is crucial to provide a good understanding of the 
linguistic situation for a bilingual or multilingual country. Which language an individual choses to use may depend on who is the interlocutor, and the situation in which the conversation takes place.

\subsection{Sociolinguistic Profile of Malaysia}

The multilingual state in Malaysia has been a result of many events and developments in the nation's history and growth. In the past, Malaya (before Malaysia was form) was first conquered by the Portuguese, followed by the Dutch and Japanese. After that, it was the British who colonized all of Malaya and the colonization by the British had the most impact compared to the other colonizers.

During the colonial period, there was generally a large number of Malayan aborigines and Malay in the country. There were also small groups of Siamese, Arabs and Proto-Malays who speak Malay. During the British colonial rule, the government had encouraged mass importation of Chinese and Indian workers to Malaya. All these had brought about a diverse mixture of speech communities that constantly came into contact with one another and consequently shaped Malaya as a multilingual country.

During British imperialism, English language was the official language in the formal domains. The "formal" domains include the legal domain, government domain and education domain. Informal domains refer to the domains where informal interactions take place, such as, in the vendor-buyer relationship in the transaction domain, or between the employer and his servant who was from different ethnic group in the workplace domain. Before the independence, English was used in English medium schools to produce the elites of the then Malayan society. For most commoners however, Malay was the lingua franca for people of various linguistic backgrounds where it is used when they communicate with each other or carrying out their trades in informal domains.

After the independence, Malaya underwent drastic changes with regard to the language policy. Bahasa Malaysia (BM) was declared as the sole national language and official language for the purpose of nation building in the year 1957. As for the English language, it was announced that it would be the second most important language (Asmah Haji Omar, 1993). Hence, enormous effort and resources have been spent in implementing BM as the medium of instruction in schools and tertiary institutions, and also establishing it as a language that can cope with the demands of the fields of science and technology. This led to English being gradually phased out as the medium of instruction.

Despite the change in the language policy, the English language was not completely neglected in the education policy. It is still taught as one of the compulsory subjects in schools. However, there also exists a unique situation in the Malaysian school system whereby vernacular languages i.e. Mandarin and Tamil, are used as the medium of instruction in the primary national type schools. As such, a large number of Malaysians who have gone through these schools are proficient in either Chinese or Tamil language. The recognition of the importance of vernacular languages was a recognition of language rights that are enshrined in the constitution. At the same time, English and Malay languages are also taught in these vernacular schools.

From the historical perspective, it is clear that languages are given different emphases in Malaysia. While Malay language is the official medium of instruction in national schools, Chinese and Tamil languages can be the medium of instruction in the primary national type schools. English is also taught as a subject in both national and national type schools. The difference between the national and national-type schools is that the former use Malay as the medium of instruction while the latter use either Chinese, Tamil or English language as the medium of instructions.

Despite this, English language remains dominant in various domains in Malaysia such as business, education, politics, tourism, employment, law, media and translation. English is entrenched as a global language and the Malaysian government sees the need for its citizens to be multilingual. Language policies govern the use of languages in education from primarily to the tertiary level. In other words, at every level there will be manifestations of language choice and use. In this study, language choice and use is focus on lecturers at the tertiary level. At this level, the language choice and use have been seen to be impacted by earlier experiences.

\subsection{Research Objectives}

This research aims to investigate the patterns of language choice and use of university lecturers in Malaysian public university. In addition, it examines if there are any significant differences between ethnicity and the field of study with the language choice and use of the English language.

\subsection{Theoretical Framework}

The domain analysis framework proposed by Fishman $(1964,1965,1968,1972)$ was adapted in this research. Fishman hypothesises that domains are the theoretical constructs that can be explained through the phenomenon of language choice and use. It is of salience in explaining language choice of large speech communities who are bilingual or multilingual.

The theoretical framework of domain analysis addresses the issues of "who" speaks "what language" to "whom" and "when". The keywords are "who", "what", "whom", and "when". "Who" refers to the bilingual or multilingual speaker, "what" refers to the language(s) of that speaker's linguistics repertoire, "whom" refers to the interlocutors in different specify domains and "when" refers to the contexts or the domains of language use. This elaboration would clarify the language choice and use of a speaker depending on his / her experiences situated in different settings, different language repertoires possessed by the speaker, different interlocutors and different topics. This theoretical framework forwarded in 1964 has been used by many researchers in the field (Ting \& Ling, 2013; Adams, Matu, \& Ongarora, 2012; Bond, Harris, Maslanka, Pickering, \& Turkoglu, 2011; Nancy, 2011; Chaudhry, Khan, \& Mahay, 2010; Dealwis, 2010; Namei, 2008; Burhanudeen, 2006). 


\section{Material and Methods}

This research follows a quantitative methodology that utilized a cross-sectional design. In this research, the researcher collected data on the pattern of language choice and use of 200 lecturers through non-probability sampling using the purposive sampling method.

The data were gathered using a survey questionnaire. The questionnaire consisted of three sections: Section A, B and C. Section A elicited information on the demographic profile of the respondents such as field of study, faculty, age, gender, ethnicity, mother tongue, and educational background. Section B focused on the patterns of language proficiency of the three ethnic groups (Malay, Chinese and Indian) in four languages (Malay, Chinese, Indian and English). Section $\mathrm{C}$ focused on the language choice and use of the lecturers with different interlocutors and in different situations. The respondents were allowed to select more than one language for each of the sub-domains because this reflects the language choice and use of a multilingual speaker. In addition, the respondents had to indicate how frequently (Frequently, Sometimes, Frequently) they choose and use the identified languages (i.e., Malay, Chinese, Indian and English) in those situations.

The questionnaire was adapted from the study of Yeh, Chan, and Cheng (2004) on language use in Taiwan. The researcher has chosen to use this questionnaire as a basic tool and it incorporated more than half of the nine criteria that determine the vitality and endangerment of a language (International Expert Meeting on UNESCO Programme: Safeguarding of the Endangered Languages, 2003). Besides, this instrument has been validated and widely used by many researchers (Mostafizar Rahman, Chan, \& Nadzimah, 2007; Leo \& Abdullah, 2013; Awal, Jaafar, Mis, \& Lateh, 2014).The questionnaire was adapted, piloted and modified to meet the researcher's requirements and objectives of the research. More items were added to Yeh, Chan, and Cheng (2004)'s questionnaire as it was felt that they would be able to elicit more pertinent information that could be useful for an insightful discussion.

The adapted questionnaire was cross-validated by several others researchers to ensure that it was free from errors and met the survey's objectives before the initial piloted questionnaire. After that, the revised questionnaire was piloted to a total of 30 lecturers from the Malaysian public university. Then, the piloted questionnaires were collected from the respondents who were invited to give comments to the questionnaire. Amendments were then made to the questionnaire based on the respondents' feedback obtained in the pilot study. In addition, internal consistency reliability judgement tests were carried out to determine whether all of the items in the questionnaire were reliable and accurate. The consistency of responses was tested using SPSS Cronbach's Alpha to estimate the proportion of variance that was systematic or consistent in a set of test scores (Bryman, 2004). The rule of thumb for the reliability coefficients is provided by George and Mallery (2003) who stated that if the Cronbach Alpha is more than 0.90 the reading is excellefnt, more than 0.80 is good, more than 0.70 is acceptable, more than 0.60 is questionable while less than 0.50 is unacceptable. The reliability coefficients for the responses on the education domain was 0.97 . Therefore, it suggested that the items in the survey questionnaire have an excellent internal consistency.

Finally, the data were analysed using the Statistical Package for the Social Sciences version 19.0 (SPSS) in which the descriptive statistics and selected aspects of inferential statistics were computed. The responses are analysed for significant similarities and differences found in the respondents' patterns of language choice and use. Subsequently, the data are reported according to frequency, cross tabulation, one-way ANOVA and independent sample t-test.

\section{Findings}

This section describes the demographic profiles and the language proficiency of the lecturers. It also provides the information on language choice and use of the three ethnic groups (Malay, Chinese and Indian) with different interlocutors, in different situations in education domain. In addition, it determines whether there are any significant differences between ethnicity and field of study with their language choice and use of English language.

\subsection{Profile of the Respondents}

The demographic background such as the field of study, age, gender, ethnicity, mother tongue and the medium of instruction experienced by the lecturers provide useful information on the respondents' daily language choice and use.

The respondents from both Sciences (S) and Social Sciences (SS) field of studies were evenly distributed (100 respondents from each field of study).

Five age categories were summarized in Figure 1 to facilitate data interpretation. Majority of the respondents were between 36 to 45 years old $(42.0 \%)$ and followed by those between 46 to 55 years old $(26.5 \%)$. Only $1.0 \%$ of the respondent was below 25 years old.

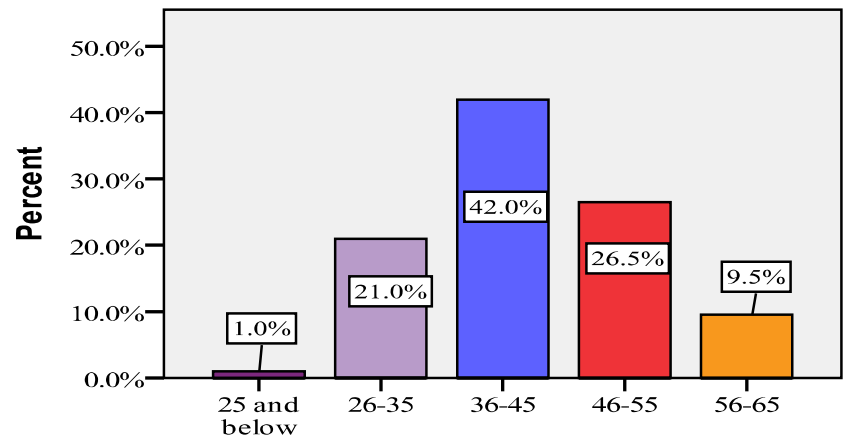

Figure 1. Age of Respondents 
The respondents had a good gender balance, with $54.5 \%(\mathrm{~N}=109)$ female and $45.5 \%(\mathrm{~N}=91)$ males.

Figure 2 portrays the ethnicity of the respondents. Most of the respondents were Malay $(\mathrm{N}=100,50.0 \%)$, followed by Chinese $(\mathrm{N}=80,40.0 \%)$; whereas Indians $(\mathrm{N}=20,10.0 \%)$ were the minority group.

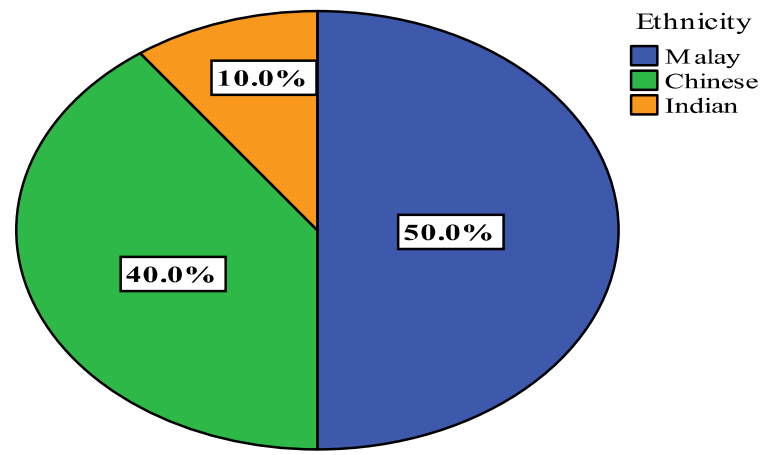

Figure 2. Ethnicity of Respondents

Table 1 illustrates the distribution of respondents' mother tongue according to their ethnicity. All Malay respondents $(100.0 \%)$ claimed that their mother tongue is Malay while $90.0 \%$ of the Chinese respondents indicated that Chinese language is their mother tongue. However, $2.5 \%$ of the Chinese respondents mentioned that their mother tongue is Malay and another 7.5\% claimed that it is English. $80.0 \%$ of the Indian respondents stated that their mother tongue is Indian language whereas another $20.0 \%$ said it is English.

Table 1. Distribution of Mother Tongue according to Ethnicity

\begin{tabular}{ccccc}
\hline & \multicolumn{4}{c}{ Mother Tongue $(\%)$} \\
\cline { 2 - 5 } Ethnicity & $\mathrm{M}$ & $\mathrm{C}$ & $\mathrm{I}$ & $\mathrm{E}$ \\
Malay & 100.0 & 0.0 & 0.0 & 0.0 \\
Chinese & 2.5 & 90.0 & 0.0 & 7.5 \\
Indian & 0.0 & 0.0 & 80.0 & 20.0 \\
\hline
\end{tabular}

Notes: M=Malay, $\mathrm{C}=$ Chinese Language (Mandarin, Cantonese, Hakka, Teochew, etc.), I= Indian Language (Tamil, Telugu, Malayalam, etc.), E= English

\subsection{Medium of Instruction Experienced by the Lecturers}

Table 2 demonstrates the medium of instruction for respondents' primary education, secondary education (Form 5 or $\mathrm{O}$ level, and Pre-U) and tertiary education (Certificate or Diploma, Bachelor, Master and Doctor of Philosophy (PhD)). Most of the respondents reported Malay language as their medium of instruction in Form 5 or O level (56.5\%), PreUniversity (46.5\%), and in primary education (45.5\%). Malay language was used in the lower education system due to the fact that Malay language is the national language of Malaysia and there is a language act that enforces all of the students who attend schools to learn Malay language.

Table 2. Medium of Instruction

\begin{tabular}{lccccccc}
\hline $\begin{array}{l}\text { Medium } \\
\text { of Instruction }\end{array}$ & \multicolumn{7}{c}{ Percentages (\%) } \\
\cline { 2 - 8 } Malay & PE & F 5 & Pre-U & CD & B & M & PhD \\
Chinese & 45.5 & 56.5 & 46.5 & 18.0 & 26.0 & 13.5 & 10.0 \\
Indian & 21.5 & 2.0 & 0.5 & 0.0 & 0.5 & 0.0 & 0.5 \\
English & 1.5 & 0.0 & 0.0 & 0.0 & 1.5 & 0.5 & 0.0 \\
Malay + Chinese & 19.5 & 22.0 & 25.0 & 19.0 & 45.0 & 61.5 & 54.0 \\
Malay + Indian & 0.5 & 3.0 & 1.0 & 0.0 & 0.5 & 0.5 & 0.0 \\
Malay + English & 1.0 & 1.0 & 1.0 & 1.0 & 0.5 & 1.0 & 1.0 \\
Chinese + English & 10.5 & 15.0 & 16.0 & 9.0 & 23.0 & 15.5 & 8.5 \\
\hline Notes: PE= Primaryyyyyyyyyyy & 0.0 & 0.0 & 0.0 & 0.0 & 1.0 & 0.5 & 1.0 \\
\hline
\end{tabular}

Notes: $\mathrm{PE}=$ Primary education, $\mathrm{F} 5=$ Form 5 or $\mathrm{O}$ level, $\mathrm{CD}=$ Certificate or Diploma, $\mathrm{B}=\mathrm{Bachel}$ or, $\mathrm{M}=$ Master, $\mathrm{PhD}=$ Doctor of Philosophy 
However, English language was used more as medium of instruction at tertiary level for graduate studies (Master $61.5 \%, \mathrm{PhD}-54.0 \%$ ) compared to undergraduate studies (Bachelor $-45.0 \%$ and Diploma $-19.0 \%$ ). Thus it is seen that English plays a significant role as a medium of instruction in university.

As for the Chinese language, it was used much less than Malay and English language. $21.5 \%$ of the respondents used Chinese language as the medium of instruction in primary education and $2.0 \%$ of them used it in Form 5 or $\mathrm{O}$ level. Only $0.5 \%$ of the respondents used it when they were studying at Pre-U, Bachelor, and Doctor of Philosophy (PhD) levels. The use of Chinese language as the medium of instruction in tertiary education could be by respondents who studied Chinese language courses.

Indian language remains the minority language that was used as medium of instruction. For instance, only $1.5 \%$ respondents used Indian language in their primary education and Bachelor while $0.5 \%$ used them in Master studies. However, none of them used Indian language in their secondary education, Pre-U, Diploma and PhD. Most preferred to enrol in English-medium schools or Malay-medium schools to get a better education and better chance to advance in their life (H.F. Schiffman, 2002).

A small proportion of respondents stated they had been exposed to more than one language as their medium of instruction in schools or universities. For example, they were exposed to Malay and Chinese, Malay and Indian, Malay and English, or Chinese and English language as their medium of instruction. This phenomenon may attribute to the fact that Malaysia is a multilingual country which enables different ethnic groups to choose and use other languages such as Chinese, Indian or English language with Malay language in pursuing their education. Besides, some of the respondents who studied in National-Type schools would learn different ethnic language together with Malay language which caused the medium of instructions to be different from the National schools.

\subsection{Language Proficiency of Lecturers}

The information on the language proficiency of the respondents is important in providing an overview of the respondents' competencies in different languages (e.g., Malay, Chinese, Indian and English) that may influence the respondents' language choice and use in different domains. The language proficiency was measured using 5-point Likert scale in four language skills (speaking, listening, reading and writing). Based on the scale, each of the skill listed a maximum score of five points and a minimum score of one point. Those who are very proficient in all of the four language skills obtained a total of twenty points. The points from the questionnaire are categorised into high $(\mathrm{H})$, medium (M) and low (L) proficient. Those who obtained 0.0 to 6.7 points are considered as having low proficiency level while respondents' obtained 6.8 to 13.3 points are considered as having medium proficiency level. Those who have obtained 13.4 to 20 points will be considered as having high proficiency level.

Table 3 illustrates the language proficiency of the three ethnic groups of lecturers (Malay, Chinese and Indian) in four languages (Malay, Chinese Indian and English). The data suggested that all of the Malay respondents identified themselves as highly proficient in Malay language (100.0\%). 92.5\% of the Chinese respondents identified themselves as highly proficient in Malay language while $7.5 \%$ of them felt that their level of proficiency in Malay is medium. $80.0 \%$ of the Indian respondents felt that their proficiency in Malay language is high, while $20.0 \%$ considered themselves to be relatively proficient (medium) in Malay language.

Table 3. Language Proficiency of Respondents

\begin{tabular}{lllll}
\hline Language(s) & Language & \multicolumn{2}{l}{ Ethnicity (\%) } \\
\cline { 3 - 5 } Malay & Proficiency & Malay & Chinese & Indian \\
& High & 100.0 & 92.5 & 80.0 \\
& Mid & 0.0 & 7.5 & 20.0 \\
Chinese & Low & 0.0 & 0.0 & 0.0 \\
& High & 0.0 & 53.8 & 0.0 \\
& Mid & 4.0 & 37.5 & 0.0 \\
Indian & Low & 96.0 & 8.8 & 100.0 \\
& High & 0.0 & 0.0 & 40.0 \\
& Mid & 0.0 & 0.0 & 30.0 \\
English & Low & 100.0 & 100.0 & 30.0 \\
& High & 85.0 & 93.8 & 95.0 \\
& Mid & 15.0 & 6.3 & 5.0 \\
& Low & 0.0 & 0.0 & 0.0 \\
\hline
\end{tabular}

Notes: High $=$ High proficiency level, Mid $=$ Medium proficiency level, Low $=$ Low proficiency level

$53.8 \%$ of the Chinese respondents felt that they are highly proficient in Chinese language and $37.5 \%$ felt that their proficiency in Chinese language is at medium level. Only $8.8 \%$ of the Chinese respondents felt that they are having low proficiency in Chinese language. It is interesting to note that $4.0 \%$ of the Malay respondents considered themselves as quite proficient (medium) in Chinese language while $96.0 \%$ of them are having low proficiency in Chinese language. In addition, as expected, all of the Indian respondents felt that their proficiency in Chinese language is low. 
Only $40.0 \%$ of the Indian respondents claimed that their proficiency in Indian language is high and $30.0 \%$ of them felt that their proficiency in Indian language is at medium level. However, all of the Malay and Chinese respondents felt that their proficiency in Indian language is low.

From the table, we observed that all of the respondents are proficient in English language and none of them claimed themselves as having low proficiency in that language. The Indian respondents claimed the highest proficiency in English $(95.0 \% \mathrm{H}, 5.0 \% \mathrm{M})$ while Chinese respondents are ranked second $(93.8 \% \mathrm{H}, 6.3 \% \mathrm{M})$. Even though Malay respondents were ranked last in English language proficiency; all of them however said that they were proficient $(85.0 \% \mathrm{H}, 15.0 \% \mathrm{M})$ in English. This seemed to indicate that generally all of the lecturers who participated in this research have a good command in English language. This may due to the fact that English language is the language of higher education and it is compulsory for professionals such as lecturers to be proficient in it. Besides, English language is the global language and it is important for the lecturers to keep pace with the global advancement and new knowledge.

\subsection{Language Choice and Use in Education Domain}

The data in this section depict the language choice and use among the lecturers with different interlocutors, settings and topics. Interlocutors refer to the lecturers and their students, supervisees or colleagues while settings refer to the place where the conversations take place and topics refer to the subject matters being discussed. For example, a Malay lecturer who chose and used English language when giving lectures in the class may choose and use Malay language in meetings. We also wanted to identify the frequency of use in each situation i.e. Rarely (R), Sometimes (S), and Frequently (F). For example, a Malay respondent may choose and use Malay language with other Malay interlocutors in the education domain but he may choose and use English language with non-Malay respondents (such as Chinese or Indian respondents) in the same domain (Burhanudeen, 2006). Such comparisons lend support to the conviction that the subjects' language choices in a given situation are not arbitrary, but governed by certain norms of appropriate language choice and use that are governed by situations as described in domain analysis.

Thirty-four education sub-domains that are further sub-categorised into formal and informal education domains have been identified. There are twenty-nine formal and five informal sub-domains within the education domain. The formal education domain refers to the domain where official communication takes place such as in lectures or for the writing of test and examination questions. On the other hand, the informal domains refer to informal or casual activities such as discussing personal matters with colleagues or students. All of the data analysed as followed were summarised in Table 4 (See Appendix).

The formal education domain consisted of the following situations:

1. Speaking to Malay Students

2. Speaking to Chinese Students

3. Speaking to Indian Students

4. Speaking to Malay Supervisees

5. Speaking to Chinese Supervisees

6. Speaking to Indian Supervisees

7. Speaking to Malay Colleagues

8. Speaking to Chinese Colleagues

9. Speaking to Indian Colleagues

10. Speaking to Malay Local Visitor(s) on Academic Matters

11. Speaking to Chinese Local Visitor(s) on Academic Matters

12. Speaking to Indian Local Visitor(s) on Academic Matters

13. Speaking to Foreign Visitor(s)

14. Giving Lectures

15. Conducting classroom Discussions

16. Talking to Students on Academic Matters

17. Writing Test Questions

18. Attending Meetings

19. Presenting Conference Papers

20. Doing Consultancy Work

21. Writing Journal Articles

22. Doing Research by Writing a Research Report

23. Doing Research by Gathering Data

24. Doing Research by Writing Literature Review 


25. Discussing Academic Matters with Colleagues
26. Using Computer Applications
27. Corresponding Through Email
28. Corresponding Through SMS
29. Corresponding Through Letter

The informal education domains consisted of the following situations:
30. Speaking to Malay Local Visitor(s) on Non-academic Matters
31. Speaking to Chinese Local Visitor(s) on Non-academic Matters
32. Speaking to Indian Local Visitor(s) on Non-academic Matters
33. Talking to Students on Personal Matters
34. Discussing Personal Matters with Colleagues

\subsection{Formal Education Domain}

In the formal education domain, more than three quarter of Malay respondents preferred the English language more than the Malay language in all of the formal sub-domains. However, a significant percentage of the Malay respondents chose and used their own ethnic (Malay) language more frequently than the English language when they speak to their Malay colleagues $(79.0 \% \mathrm{~F}, 12.0 \% \mathrm{~S})$, Malay students $(75.0 \% \mathrm{~F}, 15.0 \% \mathrm{~S})$, Malay supervisees $(73.0 \% \mathrm{~F}, 11.0 \% \mathrm{~S})$ and Malay local visitor(s) on academic matters $(65.0 \% \mathrm{~F}, 18.0 \% \mathrm{~S})$. It is also interesting that some of them chose and used the Chinese language when they speak to their Chinese supervisees (3.2\%), Chinese colleagues $(3.1 \%)$, Chinese students (3.0\%); Malay (3.0\%) and Chinese local visitor(s) on academic matters (3.1\%). However, the Malay respondents rarely chose and used Indian and Chinese language in all of the sub-domains.

The patterns of language choice and use of the Chinese respondents were similar to the Malay respondents in the formal education domain. Both of the Malay and Chinese respondents chose and used the English language very frequently and occasionally the Malay and Chinese languages in all of the sub-domains. It is interesting to find that the Chinese respondents indicated that they also chose and used Chinese language occasionally when they speak to Malay students $(1.3 \% \mathrm{~S})$, Malay supervisees $(1.3 \% \mathrm{~S})$, and Malay local visitor(s) on academic matters $(1.3 \% \mathrm{~S})$. All of them rarely chose and used the Indian language.

As for the Indian respondents, they also chose and used English language more frequently than Malay language in all of the formal education sub-domains. In addition, they resorted to Indian language when they speak to Indian colleagues (15.0\%), Indian students, Indian supervisees and Indian local visitor(s) on academic matters (5.0\%). In contrast, all of the Indian respondents rarely chose and used Chinese language.

From the data analysis for the formal education sub-domains, all of the respondents chose and used English language more frequently than other languages. Compared to the Malay respondents, the Indian and Chinese respondents chose and used English language much more frequently than the Malay respondents. Besides, the Indian and Chinese respondents stated that they chose and used Malay language too although the frequency is not as high as Malay respondents. In addition, they also chose and used a negligible amount of the ethnic languages in the formal education sub-domains.

Since all of the respondents were mostly educated in Malay or English medium schools and universities, they would be more likely to be more proficient in both English and Malay languages. The respondents also chose and used their own ethnic language when they communicate with the same ethnic as to establish a better rapport with their colleagues, students or visitors.

The high frequent use of English and Malay languages could be due to the fact that the respondents felt that it is appropriate to choose and use those languages since tertiary education in formal level requires formal varieties. Besides, it signifies the respondents' respect for their education and authority as well as to indicate their respect to the national (Malay) and official (English) language.

The ethnic languages appeared to be much less frequently used in the formal education domain. It is not surprising since in the formal domain, the standard variety (English and Malay) should be used more. A negligible amount of Chinese and Malay respondents claimed that they also chose and used Chinese language in the formal education domain. The use of Chinese language by the Chinese respondents in the education domain could be because some of the courses in the programme such as Chinese language or Chinese literature programme are taught in Chinese language. However, the use of Chinese language by Malay respondents seemed to imply that they either have learned the Chinese language in their primary education or one of their parents is of Chinese-descent.

\subsection{Informal Education Domain}

As far as the informal education domain is concerned, more than half of the Malay respondents chose and used English language frequently when they speak to Chinese $(63.9 \% \mathrm{~F}, 21.6 \% \mathrm{~S})$ and Indian local visitor(s) on non-academic matters $(64.9 \% \mathrm{~F}, 20.6 \% \mathrm{~S})$, and talk to students on personal matters $(69.0 \% \mathrm{~F}, 10.0 \% \mathrm{~S})$. However, they chose and used Malay 
language more than English language when they speak to Malay local visitor(s) on non-academic matters $(81.0 \% \mathrm{~F}$, $9.0 \% \mathrm{~S})$ and discuss personal matters with colleagues $(74.0 \% \mathrm{~F}, 12.0 \% \mathrm{~S})$. It is somewhat interesting to find that some Malay respondents chose and used Chinese language when they speak to Chinese local visitor(s) on non-academic matters $(3.1 \%)$ and talk to students on personal matters $(3.0 \%)$. In contrast, the Malay respondents rarely chose and used Indian language in the informal education domain.

As for Chinese respondents, they chose and used English language most of the time in the informal education domain and occasionally the Malay language. In addition, they chose and used some Chinese language when they speak to Chinese local visitor(s) on non-academic matters $(35.0 \% \mathrm{~F}, 11.3 \% \mathrm{~S})$, talk to students on personal matters $(81.0 \% \mathrm{~F}$, $9.0 \% \mathrm{~S})$ and discuss personal matters with colleagues $(81.0 \% \mathrm{~F}, 9.0 \% \mathrm{~S}) .2 .5 \%$ of the Chinese respondents even claimed that they chose and used Chinese language when they speak to Malay local visitor(s) on non-academic matters. On the other hand, they rarely chose and used Indian language.

Similar patterns were found between the Chinese respondents and Indian respondents in the language choice and use in the informal education domain. Both of the ethnic groups chose and used English language more frequently than Malay language. The Indian respondents also chose and used a negligible amount of Indian language when they speak with Indian local visitor(s) on non-academic matters $(10.5 \% \mathrm{~F}, 10.5 \% \mathrm{~S})$, talk to students on personal matters $(5.0 \% \mathrm{~S})$ and discuss personal matters with colleagues $(5.0 \% \mathrm{~F}, 5.0 \% \mathrm{~S})$.

For Malay respondents, even though they frequently chose and used their ethnic language (Malay) in the informal education domain, the usage was less frequent than the use of English language. The Chinese and Indian respondents also chose and used Malay language but it was lesser than the Malay respondents. The Indian and Chinese respondents chose and used English language very frequently and occasionally Malay language in their interactions. However, they also chose and used their respective ethnic languages as it is not a formal setting that required the use of either Malay or English language.

Overall, the majority of the Malay respondents chose and used Malay language with other Malay respondents in the informal education domain. With the Chinese and Indian respondents, English language was chosen and used much more frequently than other languages although the Chinese and Indian languages are their ethnic languages.

\subsection{Language Choice and Use of English Language according to Ethnicity}

A one-way ANOVA is conducted to determine if there are any significant differences between three ethnic groups (Malay, Chinese and Indian) in the dependent variables (their language choice and use of English language). A post-hoc analysis using Tukey HSD test was performed to examine which pairs of groups (Malay and Chinese, Chinese and Indian, Indian and Malay) that are significantly different from each other.

Table 5 displays the means and standard deviation for language choice and use of Malay, Chinese and Indian respondents in education domain. Malay respondents $(M=3.63, S D=0.51)$ scored the lowest mean score whereas Indian respondents $(M=3.92, S D=0.24)$ scored the highest. As for the Chinese respondents $(M=3.86, S D=0.27)$, the mean score did not differ significantly from either Malay or Indian respondents.

Table 5. Means and Standard Deviation

\begin{tabular}{ccccc}
\hline & $\mathrm{N}$ & Mean & Std. Deviation & Std. Error \\
\hline Malay & 100 & 3.63 & .51 & .05 \\
Chinese & 80 & 3.86 & .27 & .03 \\
Indian & 20 & 3.92 & .24 & .05 \\
Total & 200 & 3.75 & .42 & .03 \\
\hline
\end{tabular}

Table 6 demonstrates the result of one-way ANOVA for language choice and use among the three ethnic groups (Malay, Chinese and Indian). The table revealed that the between-group mean square was 1.43 (2.87/2); and the within-group mean square was $0.17(32.6 / 197)$. The F-ratio was $(2,197)=8.66$, and $p=0.00$ stated that the differences in the mean scores of the three ethnic groups were statistically significant.

Table 6. ANOVA Result for Language Use and Choice of English among Three Ethnic Groups

\begin{tabular}{llllll}
\hline & Sum of Squares & df & Mean Square & F & Sig. \\
\hline Between Groups & 2.87 & 2 & 1.43 & 8.66 & .00 \\
Within Groups & 32.60 & 197 & .17 & & \\
Total & 35.46 & 199 & & & \\
\hline
\end{tabular}

Table 7 illustrates the Tukey HSD post-hoc analysis test to show which of the three ethnic groups' language choice and use of English language differ from each other. The mean difference between groups of Malay and Chinese $=-0.22$, Chinese and Indian $=-0.06$, and Indian and Malay $=0.29$. The post-hoc analysis found that significant differences in language choice and use of the English language in groups of Malay and Chinese $(p=0.00)$ as well as Indian and Malay $(p=0.00)$. However, no significant differences was found between the Chinese and Indian group $(p=0.80)$ at $p<0.05$. 
In general, Indian respondents chose and used English language more frequently than Chinese and Malay respondents. However, Malay respondents chose and used less English than Indian and Chinese respondents. The Indian respondents chose and used English more frequently than the Chinese respondents but the difference was found not to be significant.

Table 7. Tukey HSD Test

\begin{tabular}{lllllll}
\hline Comparisons & $\begin{array}{l}\text { Mean } \\
\text { Difference }\end{array}$ & Std. Error & Sig. & \multicolumn{2}{c}{$95 \%$ Confidence Interval } \\
\cline { 5 - 6 } & & & & Lower Bound & Upper Bound \\
\hline Malay & Chinese & $-.22^{*}$ & .06 & .00 & -.37 & -.08 \\
Chinese & Indian & -.06 & .10 & .80 & -.30 & .18 \\
Indian & Malay & $.29^{*}$ & .01 & .01 & .053 & .52 \\
\hline
\end{tabular}

*. The mean difference is significant at the 0.05 level.

\subsection{Language Choice and Use of English Language according to Field of Study}

An independent sample t-test was performed to determine whether there are any significant differences in language choice and use of English language between Social Sciences and Sciences lecturers in education domain.

Table 8 illustrates the means and standard deviations of Social Sciences and Sciences lecturers. The Sciences lecturers attained higher mean scores $(M=3.90, S D=0.16)$ than Social Sciences lecturers. The results suggested that the Sciences lecturers chose and used English language more frequently than those in Social Sciences. Conversely, the Social Sciences lecturers scored lower mean scores than Sciences lecturers $(M=3.60, S D=0.54)$.

Table 8. Means and Standard Deviation of Social Sciences and Sciences Lecturers

\begin{tabular}{lccccc}
\hline Domain(s) & F.S & $\mathrm{N}$ & Mean & Std. Deviation & Std. Error \\
\hline Education & $\mathrm{SS}$ & 100 & 3.60 & .54 & .05 \\
& $\mathrm{~S}$ & 100 & 3.90 & .16 & .01 \\
\hline
\end{tabular}

Notes: FS = Field of Study, SS= Social Sciences, $\mathrm{S}=$ Sciences

Table 9 presents the results of independent sample t-test for Social Sciences and Sciences lecturers. The two-tailed significance test was used to determine the significant difference. The results were between Social Sciences and Sciences lecturers in language choice and use of English language in domains of education, $t(198)=-5.44, p<0.05$. The result suggests that the two groups of lecturers used English significantly different in the domains education. In the Sciences, more English is significantly used compared to the Social Sciences. This could be a result of the courses themselves, meaning that more sciences are taught in English.

Table 9. Independent Sample T-Test Results for Social Sciences and Sciences Lecturers

\begin{tabular}{|c|c|c|c|c|c|c|}
\hline & & \multicolumn{5}{|c|}{ t-test for Equality of Means } \\
\hline & & \multirow{3}{*}{$\mathrm{t}$} & \multirow{3}{*}{ df } & \multirow{3}{*}{$\begin{array}{l}\text { Sig. (2- } \\
\text { tailed) }\end{array}$} & \multirow{2}{*}{\multicolumn{2}{|c|}{$\begin{array}{c}95 \% \text { Confidence } \\
\text { Interval of the } \\
\text { Difference }\end{array}$}} \\
\hline & & & & & & \\
\hline & & & & & Lower & Upper \\
\hline \multirow{2}{*}{ Education } & Equal variances assumed & -5.44 & 198 & .00 & -.41 & -.19 \\
\hline & Equal variances not assumed & -5.44 & 116.43 & .00 & -.41 & -.19 \\
\hline
\end{tabular}

\section{Conclusion}

The study has shown the language choice and use of a particular professional group of Malaysians who are lecturers in a Malaysian public university. The findings revealed that in the formal education domain, it is observed that the English and Malay languages have been chosen and used by all of the Malay, Chinese and Indian respondents. English and Malay languages are the medium of instruction in Malaysian higher education. However, there were some Chinese respondents who stated that they chose and used Chinese language in the formal education domain. The reason is that the Chinese respondents were teaching Chinese courses such as Chinese language or Chinese literature, which required Chinese language to be the medium of instruction. In the informal education domain, all of the respondents chose and used English language most frequently although they also chose and used their own ethnic languages.

The one-way ANOVA results revealed that the language choice and use of the English language differed significantly across three ethnic groups (Malay, Chinese and Indian). The results were subject to Tukey HSD post-hoc analysis whereby significant differences were found in group between Malay and Chinese. This means that the Chinese group chose and used English language more frequently than the Malay group. Besides, significant differences were found in Indian and Malay group as the Indian group chose and used English language more frequently than the Malay group. However, the language choice and use of English language did not differ significantly between Chinese and Indian 
groups. It implies that the Indian and Chinese group chose and used English language almost equally. However, groups between Malay and Chinese; and Indian and Malay showed the most significant differences as Malay respondents chose and used less English language compared to Chinese and Indian respondents.

In terms of field of study, the independent sample t-test discovered that significant differences were identified between Sciences and Social Sciences lecturers in language choice and use of English language. There was a significant difference whereby Sciences lecturers appear to choose and use English more.

All in all, the findings have contributed to an insightful understanding of language choice and use in a multilingual setting with a complementary focus on the use of English which is not considered as an ethnic language for Malaysian communities. Nonetheless, the findings showed that this global language has gained significant grounds as a language that has become a firm choice of use among the respondents. The language choice and use of the lecturers have been impacted by the language policies that spelt out the role and status of both Bahasa Malaysia (BM) and English language.

\subsection{Recommendation of Further Studies}

Future studies can be conducted with different universities in Malaysia and differentiated between governmental universities and private universities in order for the findings of the research to be generalized to all of the lecturers in Malaysia. In addition, the research could be expanded from domain analysis to an in-depth comparison of the language choice and use between university students and university lecturers. Therefore, inferences about differences or similarities between students and professionals will be revealed.

\section{References}

Abdullah, A. R. (2013). Language Choice and Use of Malaysian Tamil Christian Youths: A Survey. Frontiers of Language and Teaching, 149-166.

Adams, Y., Matu, P. M., \& Ongarora, D. O. (2012). Language Use and Choice: A Case Study of Kinubi in Kibera, Kenya. International Journal of Humanities and Social Sciences, 99-104.

Awal, N. M., Jaafar, M. F., Mis, M. A., \& Lateh, H. (2014). Maintenance of Mother Tongue: Patterns of Language Choice at the Malaysian-Thai Border. Procedia - Social and Behavioral Sciences (pp. 282 - 287). Elsevier Lt.

Bond, M., Harris, J., Maslanka, I., Pickering, H., \& Turkoglu, D. P. (2011). Language Choice of the Polish Community in Manchester. Manchester: University of Manchester.

Bryman, A., \& Cramer, D. (2009). Quantitative Data Analysis with SPSS 14,15 and 16. London and New York: Routledge Taylor and Francis Group.

Bryman, A. (2004). Social Research Methods. Oxford: Oxford University Press.

Bryman, A. (2004). The Nature of Quantitative Research. In A. Bryman, Social Research Methods: Second Edition (pp. 61-82). New York: Oxford University Press.

Burhanudeen, H. (2006). Language and Social Behaviour. Bangi: Penerbit Universiti Kebangsaan Malaysia.

Chaudhry, S., Khan, M., \& Mahay, A. (2010). A Multilingual Family's Linguistic Profile in Manchester: A Domain Analysis of English, Urdu and Punjabi. Manchester: University of Manchester.

Dealwis, C. (2010). Language Choices of Dayak Bidayuh Undergraduates in the Friendship Domain. Borneo Research Journal, 209-220.

Ethnologue Languages of the World. (n.d.). Retrieved from http://www.ethnologue.com/showcountry.asp?name=MY

Fishman, J. A. (1989). Utilizing Societal Variables to Predict Whether Countries are Linguistically Homogeneous or Heterogeneous. In J. A. Fishman, Language and Ethnicity in Minority Sociolinguistics Perspectives (pp. 580-601). Philadelphia: Multilingual Matters.

Fishman, J. A. (1972). Domains and the Relationship between Micro- and Macro-sociolinguistics. In J. J. Gumperz, \& D. Hymes, Directions in Sociolinguistics: the Ethnography of Communication (pp. 435-453). Oxford: Basil Blackwell.

Fishman, J. A. (1972). The Sociology of Language: An Interdisciplinary Social Science Approach to Language in Society. Newbury: Rowley.

Fishman, J. A. (1970). A Brief Introduction. Newbury House Publishers.

Fishman, J. A. (1967). Bilingualism With and Without Diglossia; Diglossia With and Without Bilingualism. Journal of Social Issues, 74-75.

Fishman, J. A. (1965). Who Speaks What Language to Whom and When? La Linguistique, 67-88.

Fishman, J. A. (1964). Language Maintenance and Language Shift as a Field of Inquiry. Linguistics, 32-70.

George, D., \& Mallery, P. (2003). SPSS for Windows step by step: A simple guide and reference (4th ed.). Boston: Allyn \& Bacon.

Leo, A. R., \& Abdullah, A. N. (2013). Language Choice and Use of Malaysian Tamil Christian Youths: A Survey. Frontiers of Language and Teaching, 149-166. 
Mostafizar Rahman, A. R., Chan, S. H., \& Nadzimah, A. (2007). Patterns of language choice in the education domain: The Malaysian context. In The Second Biennial International Conference on Teaching and Learning of English in Asia : Exploring New Frontiers (TELiA2) (pp. 1-15).

Namei, S. (2008). Language Choice Among Iranians in Sweden. Journal of Multilingual and Multicutural Development, 419-437.

Nancy, H. (2011). Linguistic Choices in Multilingual Spheres: The Case of the University of Ghana Male Studies.

Omar, A. H. (1993). Language and Society in Malaysia. Kuala Lumpur: Dewan Bahasa dan Pustaka.

Ting, S.-H., \& Ling, T.-Y. (2013). Language Use and Sustainability Status of Indigenous Languages in Sarawak, Malaysia. Journal of Multilingual and Multicultural Development, 77-93.

UNESCO. (n.d.). Retrieved from

http://www.unesco.org/new/fileadmin/MULTIMEDIA/HQ/CLT/pdf/Language_vitality_and_endangerment_EN.pdf

Yeh, H.-n., Chan, H.-c., \& Cheng, Y.-s. (2004). Language Use in Taiwan: Language Proficiency and Domain Analysis.

Journal of Taiwan Normal University: Humanities and Social Sciences, 75-108.

\section{Appendix}

Table 4. Language Choice and Use in Formal and Informal Education Domain

\begin{tabular}{|c|c|c|c|c|c|c|c|c|c|c|c|c|c|}
\hline \multirow{3}{*}{ Sd. } & & \multicolumn{12}{|c|}{ Language(s) } \\
\hline & & \multicolumn{3}{|c|}{ MALAY } & \multicolumn{3}{|c|}{ CHINESE } & \multicolumn{3}{|c|}{$\overline{\text { INDIAN }}$} & \multicolumn{3}{|c|}{ ENGLISH } \\
\hline & Fr. & $\mathbf{M}$ & $\mathbf{C}$ & I & $\bar{M}$ & $\mathbf{C}$ & I & $\bar{M}$ & $\mathrm{C}$ & $\mathbf{I}$ & $\bar{M}$ & $\mathrm{C}$ & I \\
\hline \multicolumn{14}{|c|}{ Formal Domain } \\
\hline \multirow{3}{*}{1} & $\overline{\mathrm{R}}$ & 10.0 & 18.8 & 30.0 & 100.0 & 98.8 & 100.0 & 100.0 & 100.0 & 100.0 & 20.0 & 8.8 & 5.0 \\
\hline & $\mathrm{S}$ & 15.0 & 26. & 40.0 & 0.0 & 1.3 & 0.0 & 0.0 & 0.0 & 0.0 & 18.0 & 12.5 & 10.0 \\
\hline & $\mathrm{F}$ & 75.0 & 55. & 30.0 & 0.0 & 0.0 & 0.0 & 0.0 & 0.0 & 0.0 & 62.0 & 78.8 & 85.0 \\
\hline \multirow{3}{*}{2} & $\mathrm{R}$ & 23.2 & 50.1 & 60.0 & 97.0 & 61.3 & 100.0 & 100.0 & 100.0 & 100.0 & 5.1 & 2.5 & 0.0 \\
\hline & $\mathrm{S}$ & 20.2 & 22. & 20.0 & 3.0 & 23.8 & 0.0 & 0.0 & 0.0 & 0.0 & 20.2 & 10.0 & 0.0 \\
\hline & $\mathrm{F}$ & 56.6 & 27. & 20.0 & 0.0 & 15.0 & 0.0 & 0.0 & 0.0 & 0.0 & 74.7 & 87.5 & 100.0 \\
\hline \multirow{3}{*}{3} & $\mathrm{R}$ & 24.2 & 46. & 65.0 & 100.0 & 100.0 & 100.0 & 100.0 & 100.0 & 95.0 & 5.1 & 1.3 & 0.0 \\
\hline & $\mathrm{S}$ & 19.2 & 21. & 15.0 & 0.0 & 0.0 & 0.0 & 0.0 & 0.0 & 5.0 & 20.2 & 8.8 & 0.0 \\
\hline & $\mathrm{F}$ & 56.6 & 32. & 20.0 & 0.0 & 0.0 & 0.0 & 0.0 & 0.0 & 0.0 & 74.7 & 90.0 & 100.0 \\
\hline \multirow{3}{*}{4} & $\overline{\mathrm{R}}$ & 16.0 & 23. & 40.0 & 100.0 & 98.7 & 100.0 & 100.0 & 100.0 & 100.0 & 18.0 & 9.1 & 5.0 \\
\hline & $\mathrm{S}$ & 11.0 & 22. & 35.0 & 0.0 & 1.3 & 0.0 & 0.0 & 0.0 & 0.0 & 15.0 & 10.4 & 5.0 \\
\hline & $\mathrm{F}$ & 73.0 & 54. & 25.0 & 0.0 & 0.0 & 0.0 & 0.0 & 0.0 & 0.0 & 67.0 & 80.5 & 90.0 \\
\hline \multirow{3}{*}{5} & $\overline{\mathrm{R}}$ & 32.6 & 61.2 & 70.0 & 96.8 & 64.1 & 100.0 & 100.0 & 100.0 & 100.0 & 7.4 & 2.6 & 5.0 \\
\hline & $\mathrm{S}$ & 10.5 & 16. & 20.0 & 3.2 & 17.9 & 0.0 & 0.0 & 0.0 & 0.0 & 10.5 & 5.1 & 0.0 \\
\hline & $\mathrm{F}$ & 56.8 & 21.8 & 10.0 & 0.0 & 17.9 & 0.0 & 0.0 & 0.0 & 0.0 & 82.1 & 92.3 & 95.0 \\
\hline \multirow{3}{*}{6} & $\overline{\mathrm{R}}$ & 32.6 & 55.8 & 75.0 & 100.0 & 100.0 & 100.0 & 100.0 & 100.0 & 95.0 & 7.4 & 0.0 & 0.0 \\
\hline & $\mathrm{S}$ & 10.5 & 18.2 & 15.0 & 0.0 & 0.0 & 0.0 & 0.0 & 0.0 & 5.0 & 10.5 & 3.9 & 5.0 \\
\hline & $\mathrm{F}$ & 56.8 & 26. & 10.0 & 0.0 & 0.0 & 0.0 & 0.0 & 0.0 & 0.0 & 82.1 & 96.1 & 95.0 \\
\hline \multirow{3}{*}{7} & R & 9.0 & 13. & 25.0 & 100.0 & 100.0 & 100.0 & 100.0 & 100.0 & 100.0 & 28.0 & 10.1 & 5.0 \\
\hline & $\mathrm{S}$ & 12.0 & 24. & 50.0 & 0.0 & 0.0 & 0.0 & 0.0 & 0.0 & 0.0 & 12.0 & 7.6 & 10.0 \\
\hline & $\mathrm{F}$ & 79.0 & 62. & 25.0 & 0.0 & 0.0 & 0.0 & 0.0 & 0.0 & 0.0 & 60.0 & 82.3 & 85.0 \\
\hline \multirow{3}{*}{8} & $\bar{R}$ & 25.3 & 61.2 & 75.0 & 96.9 & 46.3 & 100.0 & 100.0 & 100.0 & 100.0 & 5.2 & 0.0 & 0.0 \\
\hline & $\mathrm{S}$ & 22.2 & 18. & 25.0 & 3.1 & 23.8 & 0.0 & 0.0 & 0.0 & 0.0 & 10.3 & 6.3 & 0.0 \\
\hline & $\mathrm{F}$ & 52.5 & 20. & 0.0 & 0.0 & 30.0 & 0.0 & 0.0 & 0.0 & 0.0 & 84.5 & 93.8 & 100.0 \\
\hline \multirow{3}{*}{9} & $\overline{\mathrm{R}}$ & 24.7 & 50. & 80.0 & 100.0 & 100.0 & 100.0 & 100.0 & 100.0 & 80.0 & 6.2 & 0.0 & 0.0 \\
\hline & $\mathrm{S}$ & 22.7 & 19. & 15.0 & 0.0 & 0.0 & 0.0 & 0.0 & 0.0 & 15.0 & 11.3 & 2.6 & 5.0 \\
\hline & $\mathrm{F}$ & 52.6 & 29. & 5.0 & 0.0 & 0.0 & 0.0 & 0.0 & 0.0 & 5.0 & 82.5 & 97.4 & 95.0 \\
\hline \multirow{3}{*}{10} & $\overline{\mathrm{R}}$ & 17.0 & 25. & 40.0 & 97.0 & 98.8 & 100.0 & 100.0 & 100.0 & 100.0 & 21.0 & 7.5 & 5.0 \\
\hline & $\mathrm{S}$ & 18.0 & 22. & 40.0 & 3.0 & 1.3 & 0.0 & 0.0 & 0.0 & 0.0 & 15.0 & 13.8 & 0.0 \\
\hline & $\mathrm{F}$ & 65.0 & 52. & 20.0 & 0.0 & 0.0 & 0.0 & 0.0 & 0.0 & 0.0 & 64.0 & 78.8 & 95.0 \\
\hline \multirow{3}{*}{11} & $\mathrm{R}$ & 35.7 & 66. & 75.0 & 96.9 & 72.5 & 100.0 & 100.0 & 100.0 & 100. & 6.1 & 0.0 & 5.0 \\
\hline & $\mathrm{S}$ & 14.3 & 13.8 & 20.0 & 3.1 & 11.3 & 0.0 & 0.0 & 0.0 & 0.0 & 13.3 & 6.3 & 0.0 \\
\hline & $\mathrm{F}$ & 50.0 & 20. & 5.0 & 0.0 & 16.3 & 0.0 & 0.0 & 0.0 & 0.0 & 80.6 & 93.7 & 95.0 \\
\hline & $\overline{\mathrm{R}}$ & 35.7 & 56. & 75.0 & 100.0 & 100.0 & 100.0 & 100.0 & 100.0 & 90.0 & 6.1 & 0.0 & 5.0 \\
\hline 12 & $\mathrm{~S}$ & 14.3 & 17. & 20.0 & 0.0 & 0.0 & 0.0 & 0.0 & 0.0 & 5.0 & 13.3 & 5.0 & 0.0 \\
\hline & $\mathrm{F}$ & 50.0 & 26. & 5.0 & 0.0 & 0.0 & 0.0 & 0.0 & 0.0 & 5.0 & 80.6 & 95.0 & 95.0 \\
\hline & $\mathrm{R}$ & 91.0 & 95. & 100.0 & 100.0 & 91.3 & 100.0 & 100.0 & 100.0 & 100.0 & 0.0 & 0.0 & 0.0 \\
\hline 13 & $\mathrm{~S}$ & 1.0 & 3.8 & 0.0 & 0.0 & 1.3 & 0.0 & 0.0 & 0.0 & 0.0 & 1.0 & 1.3 & 0.0 \\
\hline & $\mathrm{F}$ & 8.0 & 1.3 & 0.0 & 0.0 & 7.5 & 0.0 & 0.0 & 0.0 & 0.0 & 99.0 & 98.8 & 100.0 \\
\hline & $\bar{R}$ & 36.0 & 51.2 & 50.0 & 100.0 & 91.3 & 100.0 & 100.0 & 100.0 & 100.0 & 13.0 & 5.0 & 5.0 \\
\hline 14 & $\mathrm{~S}$ & 30.0 & 23.8 & 30.0 & 0.0 & 2.5 & 0.0 & 0.0 & 0.0 & 0.0 & 5.0 & 7.5 & 5.0 \\
\hline & $\mathrm{F}$ & 34.0 & 25. & 20.0 & 0.0 & 6.3 & 0.0 & 0.0 & 0.0 & 0.0 & 82.0 & 87.5 & 90.0 \\
\hline & R & 35.0 & 56.2 & 45.0 & 100.0 & 91.3 & 100.0 & 100.0 & 100.0 & 100.0 & 13.0 & 5.0 & 5.0 \\
\hline 15 & $\mathrm{~S}$ & 21.0 & 18.8 & 35.0 & 0.0 & 2.5 & 0.0 & 0.0 & 0.0 & 0.0 & 5.0 & 7.5 & 0.0 \\
\hline & $\mathrm{F}$ & 44.0 & 25. & 20.0 & 0.0 & 6.3 & 0.0 & 0.0 & 0.0 & 0.0 & 82.0 & 87.5 & 95.0 \\
\hline
\end{tabular}




\begin{tabular}{|c|c|c|c|c|c|c|c|c|c|c|c|c|c|}
\hline \multirow{3}{*}{16} & $\mathrm{R}$ & 33.0 & 46.3 & 40.0 & 100.0 & 91.3 & 100.0 & 100.0 & 100.0 & 100.0 & 12.0 & 5.0 & 5.0 \\
\hline & $\mathrm{S}$ & 22.0 & 27.5 & 35.0 & 0.0 & 2.5 & 0.0 & 0.0 & 0.0 & 0.0 & 10.0 & 7.5 & 10.0 \\
\hline & $\mathrm{F}$ & 45.0 & 26.3 & 25.0 & 0.0 & 6.3 & 0.0 & 0.0 & 0.0 & 0.0 & 78.0 & 87.5 & 85.0 \\
\hline \multirow{3}{*}{17} & $\mathrm{R}$ & 44.0 & 61.3 & 55.0 & 100.0 & 91.3 & 100.0 & 100.0 & 100.0 & 100.0 & 15.0 & 8.8 & 5.0 \\
\hline & $\mathrm{S}$ & 14.0 & 13.8 & 30.0 & 0.0 & 1.3 & 0.0 & 0.0 & 0.0 & 0.0 & 5.0 & 6.3 & 0.0 \\
\hline & $\mathrm{F}$ & 42.0 & 25.0 & 15.0 & 0.0 & 7.5 & 0.0 & 0.0 & 0.0 & 0.0 & 80.0 & 85.0 & 95.0 \\
\hline \multirow{3}{*}{18} & $\mathrm{R}$ & 25.0 & 28.8 & 35.0 & 100.0 & 92.5 & 100.0 & 100.0 & 100.0 & 100.0 & 19.0 & 0.0 & 5.0 \\
\hline & $\mathrm{S}$ & 20.0 & 27.5 & 50.0 & 0.0 & 1.3 & 0.0 & 0.0 & 0.0 & 0.0 & 14.0 & 5.0 & 0.0 \\
\hline & $\mathrm{F}$ & 55.0 & 43.8 & 15.0 & 0.0 & 6.3 & 0.0 & 0.0 & 0.0 & 0.0 & 67.0 & 95.0 & 95.0 \\
\hline \multirow{3}{*}{19} & $\mathrm{R}$ & 56.0 & 72.5 & 72.5 & 100.0 & 92.5 & 100.0 & 100.0 & 100.0 & 100.0 & 7.0 & 5.0 & 5.0 \\
\hline & $\mathrm{S}$ & 7.0 & 13.8 & 13.8 & 0.0 & 0.0 & 0.0 & 0.0 & 0.0 & 0.0 & 6.0 & 2.5 & 0.0 \\
\hline & $\mathrm{F}$ & 37.0 & 13.8 & 13.8 & 0.0 & 7.5 & 0.0 & 0.0 & 0.0 & 0.0 & 87.0 & 92.5 & 95.0 \\
\hline \multirow{3}{*}{20} & $\mathrm{R}$ & 47.4 & 59.5 & 60.0 & 100.0 & 91.1 & 100.0 & 100.0 & 100.0 & 100.0 & 6.2 & 2.5 & 5.0 \\
\hline & $\mathrm{S}$ & 9.3 & 15.2 & 35.0 & 0.0 & 2.5 & 0.0 & 0.0 & 0.0 & 0.0 & 8.2 & 6.3 & 0.0 \\
\hline & $\mathrm{F}$ & 43.3 & 25.3 & 5.0 & 0.0 & 6.3 & 0.0 & 0.0 & 0.0 & 0.0 & 85.6 & 91.1 & 95.0 \\
\hline \multirow{3}{*}{21} & $\mathrm{R}$ & 67.0 & 80.0 & 75.0 & 100.0 & 92.5 & 100.0 & 100.0 & 100.0 & 100.0 & 11.0 & 3.8 & 0.0 \\
\hline & $\mathrm{S}$ & 0.0 & 3.8 & 20.0 & 0.0 & 0.0 & 0.0 & 0.0 & 0.0 & 0.0 & 3.0 & 3.8 & 0.0 \\
\hline & $\mathrm{F}$ & 33.0 & 16.3 & 5.0 & 0.0 & 7.5 & 0.0 & 0.0 & 0.0 & 0.0 & 86.0 & 92.5 & 100.0 \\
\hline \multirow{3}{*}{22} & $\mathrm{R}$ & 66.0 & 76.3 & 75.0 & 100.0 & 92.5 & 100.0 & 100.0 & 100.0 & 100.0 & 12.0 & 5.0 & 5.0 \\
\hline & $\mathrm{S}$ & 1.0 & 10.0 & 20.0 & 0.0 & 0.0 & 0.0 & 0.0 & 0.0 & 0.0 & 2.0 & 5.0 & 0.0 \\
\hline & $\mathrm{F}$ & 33.0 & 13.8 & 5.0 & 0.0 & 7.5 & 0.0 & 0.0 & 0.0 & 0.0 & 86.0 & 90.0 & 95.0 \\
\hline \multirow{3}{*}{23} & $\mathrm{R}$ & 57.0 & 68.8 & 70.0 & 100.0 & 88.8 & 100.0 & 100.0 & 100.0 & 100.0 & 12.0 & 5.0 & 5.0 \\
\hline & $\mathrm{S}$ & 4.0 & 12.5 & 25.0 & 0.0 & 3.8 & 0.0 & 0.0 & 0.0 & 0.0 & 3.0 & 6.3 & 0.0 \\
\hline & $\mathrm{F}$ & 39.0 & 18.8 & 5.0 & 0.0 & 7.5 & 0.0 & 0.0 & 0.0 & 0.0 & 85.0 & 88.8 & 95.0 \\
\hline \multirow{3}{*}{24} & $\mathrm{R}$ & 65.0 & 81.3 & 75.0 & 100.0 & 92.5 & 100.0 & 100.0 & 100.0 & 100.0 & 12.0 & 6.3 & 5.0 \\
\hline & $\mathrm{S}$ & 1.0 & 5.0 & 20.0 & 0.0 & 0.0 & 0.0 & 0.0 & 0.0 & 0.0 & 3.0 & 3.8 & 0.0 \\
\hline & $\mathrm{F}$ & 34.0 & 13.8 & 5.0 & 0.0 & 7.5 & 0.0 & 0.0 & 0.0 & 0.0 & 85.0 & 90.0 & 95.0 \\
\hline \multirow{3}{*}{25} & $\mathrm{R}$ & 22.0 & 32.5 & 35.0 & 100.0 & 80.0 & 100.0 & 100.0 & 100.0 & 100.0 & 10.0 & 0.0 & 0.0 \\
\hline & $\mathrm{S}$ & 10.0 & 27.5 & 55.0 & 0.0 & 6.3 & 0.0 & 0.0 & 0.0 & 0.0 & 12.0 & 7.5 & 0.0 \\
\hline & $\mathrm{F}$ & 68.0 & 40.0 & 10.0 & 0.0 & 13.8 & 0.0 & 0.0 & 0.0 & 0.0 & 78.0 & 92.5 & 100.0 \\
\hline \multirow{3}{*}{26} & $\mathrm{R}$ & 71.0 & 70.0 & 70.0 & 100.0 & 86.3 & 100.0 & 100.0 & 100.0 & 100.0 & 3.0 & 0.0 & 0.0 \\
\hline & $\mathrm{S}$ & 9.0 & 13.8 & 25.0 & 0.0 & 2.5 & 0.0 & 0.0 & 0.0 & 0.0 & 6.0 & 2.5 & 0.0 \\
\hline & $\mathrm{F}$ & 20.0 & 16.3 & 5.0 & 0.0 & 11.3 & 0.0 & 0.0 & 0.0 & 0.0 & 91.0 & 97.5 & 100.0 \\
\hline \multirow{3}{*}{27} & $\mathrm{R}$ & 24.0 & 51.3 & 50.0 & 100.0 & 81.3 & 100.0 & 100.0 & 100.0 & 100.0 & 6.0 & 0.0 & 0.0 \\
\hline & $\mathrm{S}$ & 13.0 & 17.5 & 40.0 & 0.0 & 11.3 & 0.0 & 0.0 & 0.0 & 0.0 & 14.0 & 5.0 & 0.0 \\
\hline & $\mathrm{F}$ & 63.0 & 31.3 & 10.0 & 0.0 & 7.5 & 0.0 & 0.0 & 0.0 & 0.0 & 80.0 & 95.0 & 100.0 \\
\hline \multirow{3}{*}{28} & $\mathrm{R}$ & 20.0 & 60.0 & 50.0 & 100.0 & 77.5 & 100.0 & 100.0 & 100.0 & 100.0 & 9.0 & 1.3 & 0.0 \\
\hline & $\mathrm{S}$ & 16.0 & 13.8 & 45.0 & 0.0 & 6.3 & 0.0 & 0.0 & 0.0 & 0.0 & 19.0 & 3.8 & 0.0 \\
\hline & $\mathrm{F}$ & 64.0 & 26.3 & 5.0 & 0.0 & 16.3 & 0.0 & 0.0 & 0.0 & 0.0 & 72.0 & 95.0 & 100.0 \\
\hline & $\mathrm{R}$ & 20.0 & 37.5 & 30.0 & 100.0 & 80.0 & 100.0 & 100.0 & 100.0 & 100.0 & 9.0 & 0.0 & 0.0 \\
\hline 29 & $\mathrm{~S}$ & 12.0 & 16.3 & 45.0 & 0.0 & 10.0 & 0.0 & 0.0 & 0.0 & 0.0 & 15.0 & 13.8 & 5.0 \\
\hline & $\mathrm{F}$ & 68.0 & 46.3 & 25.0 & 0.0 & 10.0 & 0.0 & 0.0 & 0.0 & 0.0 & 76.0 & 86.3 & 95.0 \\
\hline & & & & & & mal E & ucation & Domai & & & & & \\
\hline & $\overline{\mathrm{R}}$ & 10.0 & 20.0 & 31.6 & 100.0 & 97.5 & 100.0 & 100.0 & 100.0 & 100.0 & 30.0 & 8.8 & 0.0 \\
\hline 30 & $\mathrm{~S}$ & 9.0 & 16.3 & 52.6 & 0.0 & 2.5 & 0.0 & 0.0 & 0.0 & 0.0 & 21.0 & 15.0 & 5.3 \\
\hline & $\mathrm{F}$ & 81.0 & 63.8 & 15.8 & 0.0 & 0.0 & 0.0 & 0.0 & 0.0 & 0.0 & 49.0 & 76.3 & 94.7 \\
\hline & $\mathrm{R}$ & 30.9 & 67.5 & 63.2 & 96.9 & 53.8 & 100.0 & 100.0 & 100.0 & 100.0 & 14.4 & 2.5 & 0.0 \\
\hline 31 & $\mathrm{~S}$ & 10.3 & 20.0 & 36.8 & 3.1 & 11.3 & 0.0 & 0.0 & 0.0 & 0.0 & 21.6 & 8.8 & 0.0 \\
\hline & $\mathrm{F}$ & 58.8 & 12.5 & 0.0 & 0.0 & 35.0 & 0.0 & 0.0 & 0.0 & 0.0 & 63.9 & 88.8 & 100.0 \\
\hline & $\mathrm{R}$ & 30.9 & 53.8 & 68.4 & 100.0 & 100.0 & 100.0 & 100.0 & 100.0 & 78.9 & 14.4 & 0.0 & 0.0 \\
\hline 32 & $\mathrm{~S}$ & 10.3 & 13.8 & 31.6 & 0.0 & 0.0 & 0.0 & 0.0 & 0.0 & 10.5 & 20.6 & 8.8 & 0.0 \\
\hline & $\mathrm{F}$ & 58.8 & 32.5 & 0.0 & 0.0 & 0.0 & 0.0 & 0.0 & 0.0 & 10.5 & 64.9 & 91.3 & 100.0 \\
\hline & $\mathrm{R}$ & 17.0 & 35.0 & 30.0 & 97.0 & 81.3 & 100.0 & 100.0 & 100.0 & 95.0 & 21.0 & 3.8 & 5.0 \\
\hline 33 & $\mathrm{~S}$ & 25.0 & 35.0 & 50.0 & 3.0 & 6.3 & 0.0 & 0.0 & 0.0 & 5.0 & 10.0 & 12.5 & 10.0 \\
\hline & $\mathrm{F}$ & 58.0 & 30.0 & 20.0 & 0.0 & 12.5 & 0.0 & 0.0 & 0.0 & 0.0 & 69.0 & 83.8 & 85.0 \\
\hline & $\mathrm{R}$ & 14.0 & 25.0 & 45.0 & 100.0 & 56.3 & 100.0 & 100.0 & 100.0 & 90.0 & 19.0 & 0.0 & 0.0 \\
\hline 34 & $\mathrm{~S}$ & 12.0 & 31.3 & 45.0 & 0.0 & 27.5 & 0.0 & 0.0 & 0.0 & 5.0 & 24.0 & 12.5 & 0.0 \\
\hline & $\mathrm{F}$ & 74.0 & 43.8 & 10.0 & 0.0 & 16.3 & 0.0 & 0.0 & 0.0 & 5.0 & 57.0 & 87.5 & 100.0 \\
\hline
\end{tabular}

Notes: Sd. = Sub-domain, F. = Frequency of Use, $\mathrm{M}=$ Malay Respondents, $\mathrm{C}=$ Chinese Respondents,

$\mathrm{I}=$ Indian Respondents, $\mathrm{R}=$ Rarely, $\mathrm{S}=$ Sometimes, $\mathrm{F}=$ Frequently 